\title{
Supply Chain Finance for Targeted Poverty Alleviation: A Case Study of Suning
}

\author{
Shanliang Li ${ }^{a}$, Shan Yan ${ }^{\mathrm{b}, 1}$ and Liwen Liu ${ }^{\mathrm{c}}$ \\ a, b, c School of Politics and Public Administration, Suzhou University, China
}

\begin{abstract}
The sudden emergence of 'COVID-19' in 2020 has tightened traffic control in various places, which has posed a huge challenge to the agricultural product supply chain. This research introduces the perspective of supply chain finance, uses in-depth case study methods, and takes Suning's agricultural supply chain finance as an example to discuss how e-commerce companies relying on big data adopt agricultural supply chain finance practices to promote accurate poverty alleviation. By analyzing Suning's four agricultural supply chain financial operation models, we find that the internal and external stakeholders of the enterprise are the driving factors for enterprises to adopt agricultural supply chain finance, and the adoption of agricultural supply chain finance measures has brought economic benefits and social benefits to enterprises benefit. Advanced big data tools, fintech and cooperation with other partners are necessary to adopt agricultural supply chain financial measures.
\end{abstract}

Keywords. Agricultural Finance; Targeted Poverty Alleviation; Supply Chain Finance; China; Suning; Case Study

Acknowledgements: We acknowledge the financial support of National Social Science Foundation of China Grants No. 18BGL060.

\section{Introduction}

Recently, concern about Targeted Poverty Alleviation and Financial poverty alleviation has risen in academia and industry. Resolving the current huge financing gap of poverty alleviation requires the participation of financial institutions at all levels, and the use of modern big data technology to launch innovative financial products, thereby improving the efficiency of poverty management. As a new financial model of "industry + finance", supply chain finance meets the innovative and diverse requirements of financial poverty alleviation [1]. Although the development of supply chain finance is an inherent requirement of "targeted poverty alleviation", information about how companies implement supply chain finance practices to help "targeted poverty alleviation" is still limited. This study takes Suning as an example and show how innovative measures of supply chain finance are used in the field of "Targeted Poverty Alleviation".

Despite increasing attention and efforts from scholar to the development of financial poverty alleviation and targeted poverty alleviation, the link between agricultural supply chain finance and targeted poverty alleviation has been neglected.

\footnotetext{
${ }^{1}$ Shan Yan, School of Politics and Public Administration, Suzhou University, China; E-mail: yanshan0610@126.com
} 
Inclusive finance can increase the income of poor farmers by releasing the rural credit constraint mechanism [2]. Some studies believe that the development of rural inclusive finance can further promote economic development and the optimization of broad income distribution, and indirectly achieve the results of income growth and poverty alleviation through the "trickle-down effect" [3]. However, for the internal connection between agricultural supply chain finance and targeted poverty alleviation, in particular, there are relatively few financial supply chain finance tools for e-commerce enterprises supported based on big data platforms.

In recent years, E-commerce giants represented by Alibaba, JD.com and Suning have actively explored rural supply chain financial services and developed various types of financial products to ease the financing constraints of upstream and downstream agricultural enterprises [4]. With the help of its advanced big data technology, E-commerce companies have built financial targeted poverty alleviation platforms to achieve accurate identification of poor households, thereby realizing effective allocation and dynamic supervision of financial poverty alleviation resources. However, there are still little researches on Suning's agricultural supply chain financial practices. The purpose of this paper is to study how Suning's agricultural supply chain financial solutions can help target poverty alleviation, and apply exploratory single case study methods to solve the following problems:

Question 1: What specific agricultural supply chain finance solutions does Suning use to help targeted poverty alleviation?

Question 2: What are the driving factors affecting Suning's adoption of agricultural supply finance initiatives?

Question 3: How do these agricultural supply chain financial initiatives work?

\section{Literature review}

\subsection{Agricultural supply chain finance and targeted poverty alleviation}

The supply chain finance has a natural adaptability to solve such financing problems. Agricultural supply chain finance is also called agricultural industry chain finance, which is essential to explore the issue of financing and rational use of capital from the perspective of agriculture [5]. At present, scholars have conducted in-depth research on agricultural supply chain finance from different perspectives, and have achieved certain achievements.

The agricultural supply chain financial model can be divided into the operating mechanism of upstream suppliers, agricultural product processing enterprises and downstream distributors suitable for agriculture based on different links of the supply chain. The supply chain finance products for the upstream suppliers of the agricultural supply chain are mainly to solve the problem of shortage of funds for upstream farmers [6], including order financing, account receivable financing and warehouse financing, which are suitable for the supply of downstream agricultural distributors [7]. With the vigorous development of artificial intelligence, blockchain, cloud computing and big data, supply chain finance has also ushered in a new stage of fintech promotion, which is reflected in the agricultural supply chain finance field as the main body leading supply chain financial activities no longer limited to agricultural core enterprises, ecommerce platform dominance has become a new model [8]. 
In the context of China's vigorous development of inclusive finance, the combination of agricultural supply chain finance and targeted poverty alleviation has deepened the reform of financial services in rural areas. Many studies show the relationship between inclusive financial development and poverty alleviation. Zhu Yiming and others showed that inclusive financial development can effectively reduce poverty by promoting economic growth, but this effect is the heterogeneity of different income groups [9]. Zhang Yan and Wang Xiaozhi believe that in order to ensure the realization of the overall goal of poverty reduction, it is necessary to formulate an overall plan for poverty reduction by e-commerce [10], strengthen infrastructure construction, promote poverty alleviation by e-commerce, and improve the accuracy of targeted poverty reduction.

The rise of big data and financial technology has provided scholars with new research ideas. Yan Fei and others conducted research on financial targeted poverty alleviation from the perspective of big data, and proposed that the use of big data can more effectively explore the root causes of poverty and effectively share financial precision poverty alleviation information[11]. Dong Yufeng and others believe that the key to breaking through the practical difficulties of traditional financial poverty alleviation lies in leveraging the advantages of digital technology to improve risk controllability [12]. The link between big data technology and financial poverty alleviation is gradually becoming a new research trend, Strengthening the application of big data technology has a significant improvement effect in optimizing the digital financial service environment in poor areas.

In recent years, the field of agricultural finance research has continued to develop, especially in developing countries. Although agricultural finance has been studied for decades, the focus is mainly on factors related to its implementation and the importance of economic development or social welfare. Few studies involve technical, economic and social aspects of agricultural finance. Therefore, agricultural finance should be investigated from a complex perspective.

\subsection{Stakeholders}

Stakeholders are defined as "any group or individual that can influence or be affected by the achievement of organizational goals" [13]. Stakeholder theory arises from how managers can more effectively solve the problems of key stakeholder groups. Managers think of stakeholders based on their views and therefore act as critical interpreters of stakeholder influence [14]. After evaluating which stakeholders are significant, the stakeholder's management concept then determines how the company's strategy will be affected.

Internal stakeholders, including investors and employees, are key allies in the success or failure of any company's strategy. Employees (all kinds) who support the company's environmental goals are more likely to find a job in it and (once there) continue to be employed [15]. They may also express satisfaction or dissatisfaction through direct discussions with company executives or company boards. The dissatisfaction of management and non-management employees can be expressed by terminating employment. External stakeholders include social stakeholders and regulators [16]. The increasing influence of social stakeholders is one of the important considerations in the company's strategic decision-making [17]. These stakeholders have the ability to mobilize public opinion to support or oppose the company. Social 
stakeholders often use indirect methods to influence company behavior because they lack direct economic interests in the organization.

In this study, when analyzing the motivation of Suning's implementation of the agricultural supply chain financial solution, based on the theoretical background of stakeholders, it explored the external and internal stakeholders' role in promoting Suning.

\section{Research Methodology}

Given the exploratory nature of this method, in-depth case study is adopted to investigate the agricultural finance practice of a company and its relationship with targeted poverty alleviation. A case study focuses on the "what" and "how" questions. The in-depth case study is applicable to explore causality and mechanism. In addition, on the basis of a single case study, we need to find the framework of the financial supply chain financial practice of the e-commerce core enterprise, and then test it through multiple case studies.

\subsection{Research Framework}

A case study initially considers the research questions and framework, so we design a research framework (see Figure 1) to answer our research questions. The adoption of a certain agricultural financial solution is driven by different stakeholders, and the implementation of the agricultural supply chain financial solution requires a guarantee method, which can be regarded as a regulatory variable.

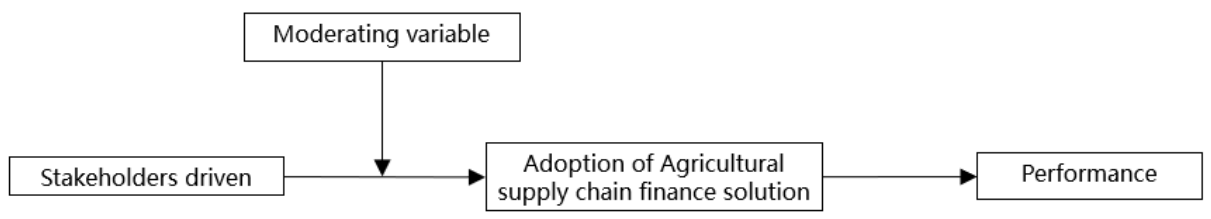

Figure 1. Research Framework.

\subsection{Case Selection}

Suning was established in 1990, and after more than 20 years it has developed into a well-deserved giant in China's chain retail industry. In 2004, Suning (stock code 002024) Group Co., Ltd. was listed on the Shenzhen Stock Exchange, becoming the first home appliance chain enterprise to be listed on the IPO in China. Suning ranked first among the top 100 Chinese chains from 2009 to 2012. Since 2009, the traditional retail industry has been violently impacted by e-commerce, which forced Suning to complete the industrial transformation and upgrade [18]. With its broad and deep offline market foundation, Suning has created a unique ecosystem of "O2O".

In recent years, some leading businesses have successively developed agricultural financial services in China. Among these platforms, Suning has a strong representative for the following reasons. First of all, Suning Finance, as a financial company of Suning, has been sticking to the 020 strategy since its establishment, creating a complete closed-loop financial ecosystem [19], Suning Finance achieved a transaction 
scale of over one trillion in 2018, with more than 70 million active members. Secondly, Suning's supply chain financial business relies on Suning E-Commerce platform, accumulating massive customer resources of small, medium and micro enterprises, and deeply integrating with the real industry to create supply chain financial products that serve a variety of financing objects. In addition, Suning has been actively exploring the agricultural finance model and implementing the core of "inclusive finance". In May 2016, the Ministry of Rural Finance was specially established to build a closed-loop agricultural product supply chain of "finance + e-commerce + agricultural production". Suning's big data platform and advanced technical means accurately identify the targets of poverty alleviation, accurately predict the amount of poverty alleviation, and use financial means to achieve precise poverty alleviation.

\subsection{Data Collection}

This case study starts with data collection and selects a combination of secondhand data and first-hand data collection. Among them, the first-hand information includes: (1) Face-to-face interviews with senior managers and front-line employees of Suning finance department. The interviews were recorded throughout the interview, and the interview materials were confirmed and updated through WeChat, email and other channels. (2) The research team went to the Suning headquarters to conduct a field survey, conducted random interviews and experienced Suning's supply chain financial product services. The collection of second-hand materials includes: (1) Use "Suning", "Suning Agricultural Finance", "Suning Targeted Poverty Alleviation", and "Suning Supply Chain Finance" as keywords to search for relevant documents published in CSSCI and core journals from 2009 to 2019; (2) Through Suning's official website, Suning Financial Research Institute, Suning's official WeChat public account, and other Suning internal channels; (3) Obtain Suning's 2009-2019 financial report and social responsibility report through Guotai' an database and wind database.

\subsection{Coding and Data Analysis}

The data analysis method of this study is data coding and classification, and then to demonstrate the research issues raised. For first-hand materials, interview tapes are transcribed into text materials for easy coding. According to the main issues of the research-the driving factors, specific measures, and benefits of agricultural supply chain financial practices, we analyze the first-hand and second-hand data. Among the driving factors and benefits, we follow the theoretical framework of stakeholders, according to government, investors, customers, employees, and external supervisors are classified.

In order to ensure the reliability of the coding, we adopted the independent coding by the researchers, and then checked it, and finally obtained the data coding of the explanation source that is necessary for the research framework. In order to ensure the reliability of the coding, we adopted the independent coding by the researchers, and then checked it, and finally obtained the data coding of the explanation source that is necessary for the research framework. The specific process is as follows: First, two members of the research team respectively code a second-hand data; Second, the two members discuss and check the content of the differences in the encoded entries in the independent encoding process, and strive to reach agreement opinion; Finally, the other two members of the data research team of the research team will review the coding 
results of the second round. If there are still differences in this round, the coding analysis of the differences will be discarded. Finally, in order to ensure that the obtained concepts are highly consistent with the corresponding descriptions, the research team sent the data and preliminary conclusions to Suning, and the final confirmation was made only after confirmation by relevant departments. Table 1 shows the encoding results.

Table 1. Examples of codes

\begin{tabular}{|c|c|c|}
\hline Category & Code & Original Quotes \\
\hline \multirow[t]{2}{*}{ External Stakeholders } & Government & $\begin{array}{c}\text { "We will take targeted poverty alleviation as the } \\
\text { main line to achieve financial poverty } \\
\text { alleviation + e-commerce poverty alleviation }+ \\
\text { industrial poverty alleviation and technology } \\
\text { poverty alleviation." }\end{array}$ \\
\hline & Farmers & $\begin{array}{c}\text { "President Xi has repeatedly emphasized that } \\
\text { people's longing for a better life is our goal of } \\
\text { struggle." }\end{array}$ \\
\hline \multirow[t]{2}{*}{ Internal Stakeholders } & Shareholders & $\begin{array}{l}\text { "Suning should promote the integration of } \\
\text { online and offline to deepen rural and remote } \\
\text { areas, practice social responsibility." }\end{array}$ \\
\hline & Employees & $\begin{array}{l}\text { "The weakening of the Internet dividend has } \\
\text { transformed the competitive landscape of major } \\
\text { e-commerce businesses from online to offline. } \\
\text { Financial poverty alleviation is an important } \\
\text { measure to maintain the competitive advantages } \\
\text { of enterprises." }\end{array}$ \\
\hline \multirow[t]{3}{*}{ Performance Society } & $\begin{array}{l}\text { Promote government } \\
\text { "Targeted Poverty } \\
\text { Alleviation" }\end{array}$ & $\begin{array}{l}\text { "Suning won the ' } 2017 \text { China's Listed } \\
\text { Companies' Targeted Poverty Alleviation } \\
\text { Innovation Case "and became the only winner } \\
\text { in the retail industry in this award." }\end{array}$ \\
\hline & $\begin{array}{l}\text { Conducive to farmers' } \\
\text { stable production and } \\
\text { sustainable operation }\end{array}$ & $\begin{array}{l}\text { "Suning Finance will give full play to its } \\
\text { resource advantages, rely on advanced financial } \\
\text { technology and rich financial products, provide } \\
\text { comprehensive inclusive financial services for } \\
\text { the general public and small and medium-sized } \\
\text { enterprises in Yichun City, use financial means } \\
\text { to promote targeted poverty alleviation, and } \\
\text { help the economy of Yichun City. Further } \\
\text { development and comprehensive improvement } \\
\text { of the quality of life of local citizens." }\end{array}$ \\
\hline & $\begin{array}{l}\text { Improve corporate social } \\
\text { image and social } \\
\text { responsibility disclosure }\end{array}$ & $\begin{array}{l}\text { It is reported that Suning Public Welfare has } \\
\text { donated more than } 1.1 \text { billion yuan in total over } \\
\text { the past } 27 \text { years. There are also a large number } \\
\text { of materials used for public welfare charities. } \\
\text { Suning Public Welfare's love image and social } \\
\text { responsibility have been fully demonstrated. }\end{array}$ \\
\hline \multirow[t]{2}{*}{ Performance Economy } & $\begin{array}{l}\text { Business expansion and } \\
\text { innovation }\end{array}$ & $\begin{array}{l}\text { "After the traditional retailers were shocked and } \\
\text { withered by online opponents, Suning returned } \\
\text { to the market with a high-profile attitude, to } \\
\text { achieve the goal of covering the entire scene } \\
\text { online and offline, from cities to counties." }\end{array}$ \\
\hline & $\begin{array}{l}\text { Financial nurturing retail } \\
\text { business }\end{array}$ & $\begin{array}{l}\text { "Smart retail is rebuilding people, goods and } \\
\text { field, but also urgently needs matching financial } \\
\text { services. At present, new finance has begun to } \\
\text { penetrate into the scene, which has played a } \\
\text { catalytic role in the integration of online and } \\
\text { offline." }\end{array}$ \\
\hline
\end{tabular}


On the financial track, Suning Finance has fully tapped the resources of the Suning Ecosystem, continuously increasing its penetration rate, and achieving coordinated development. From payment to consumer loans, to extended warranty services, to corporate loan services, Suning Finance can provide one-stop financial solutions for consumers and corporate customers in the Suning ecosystem.

\section{Case Study}

\subsection{Description}

Suning has practiced agricultural supply chain finance with specific supply chain financial products as solutions to serve individual farmers and agricultural enterprises.

\subsubsection{Model 1: Suning Enterprise Loan}

In recent years, Suning Finance has launched Suning Enterprise Loan service for agricultural enterprises (Operation mode was shown in Figure 2). In order to help agricultural enterprises break the capital restrictions, Suning launched the Suning Enterprise Loan at a low rate of interest, and allowed the upstream and downstream of agricultural core enterprises to apply for Suning Enterprise Loan based on their real trade to maintain the operation of the supply chain. Apart from producing products to the order delivery, core enterprises can sell products on Suning E-Commerce Platform, greatly expanding the sales channels. Suning Enterprise Loan solves the financing difficulty caused by information asymmetry between agricultural enterprises and traditional banks. As a bridge of real enterprises, Suning is not only a financial platform, but also a supplier of consumers, which forms a dual agricultural supply chain. Suning Enterprise Loan as a finance service provided by Suning Finance to agricultural enterprises effectively alleviates the capital pressure of prepayment and benefits the production and market of agricultural products from the supply side, fulfilling Targeted Poverty Alleviation.

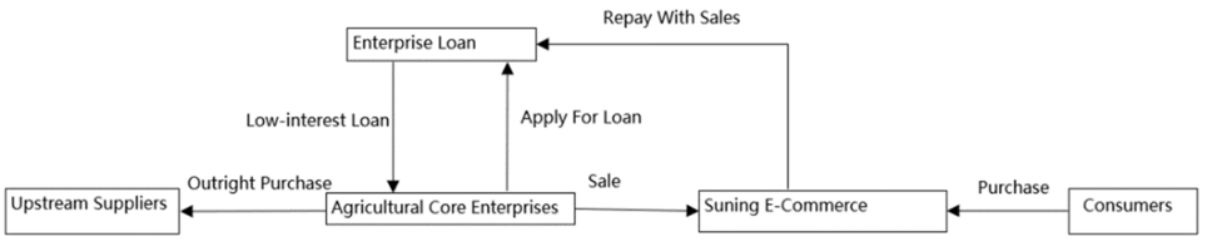

Figure 2. Suning Enterprise Loan model

\subsubsection{Model 2: Suning Agriculture Loan}

In practice, farmers and small agricultural firms have minor business scales and low credit records, certainly difficult to apply for loans from traditional financial 
institutions such as banks[20]. In August 2016, Suning Finance announced to cooperate with Agricultural Installment to launch Suning Agriculture Loan which's operation mode is presented in Figure 3. Agricultural Installment, an installment especially serving the rural market, has set up more than 150 county-level offline branches, whose business covers more than 10000 surrounding villages and towns, serving more than 350,000 farmers in the country. As an important practice of $\mathrm{O} 2 \mathrm{O}$ mode, the alliance between Suning Finance and Agricultural Installment is actually the combination of advanced technology and a powerful database. At present, the weekly amount of Suning Agriculture Loan for farmers is more than 8 million Yuan, while the total loan has reached 500 million yuan. It is estimated that about 1 billion yuan of agricultural loans will be invested in the national market in various ways within 2-3 years. Suning Agriculture Loan is an important way for Suning Finance to enter the rural financial market with the help of the third-party platform.

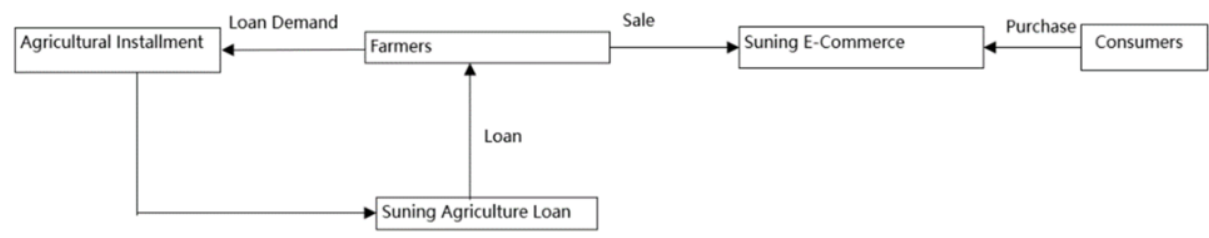

Figure3 Suning Agriculture Loan model

\subsubsection{Model 3: Suning Willful Pay}

In addition to providing financial support at the supply side to maintain stable agricultural production, Suning Finance also pays attention to the layout of the consumer side in the strategic blueprint of rural finance. In order to improve the standard of consumption of farmers, Suning Willful Pay help farmers meet the daily consumption demand by providing micro-credit. (See Figure 4) Through micro-credit, farmers can spend on Suning E-Commerce in the current month and pay bills without interest next month. The payment can be finished in one, three, six or twelve months with a monthly interest rate of $0.9 \%$. Undoubtedly, Suning Willful Pay is an important practice for Suning Finance to realize inclusive finance in rural areas. Farmers are encouraged to use Suning Finance payment product "YIFUBAO" for consumption, so that the both closed-loop payment and closed-loop consumption have achieved. Besides, credit risks have been mitigated for the connection to The People's Bank of China.

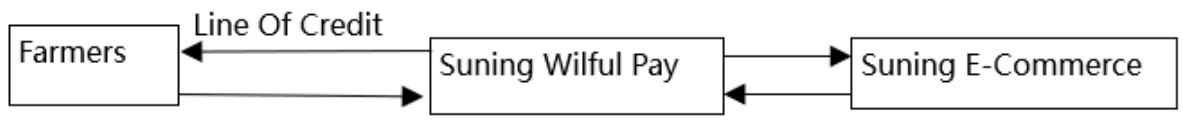

Figure 4 Suning Willful Pay 


\subsubsection{Model 4: Suning Willful Loan}

Ordinarily, farmers are evaluated as low-quality customers without repayment ability and deposit by traditional financial institutions such as banks so it is hard for them to apply for bank loans [21]. Suning is committed to providing farmers with comprehensive financial services in the whole product chain, such as credit loans and cash loans. At present, Suning Finance has promoted Suning Willful Loan, a personal loan product for farmers to pay offline with cash. Suning Willful Loan allows all farmers to have a certain amount of loans according to their credit level and repayment records, and its operation mode is illustrated in Figure 5. As a kind of small loan, Suning Willful Loan makes it possible for the borrower to achieve a cash loan after a successful application. Furthermore, Suning Finance Big Data has built a real-time risk monitoring system, relying on abundant resources online and offline to let farmers approach offline consumption.

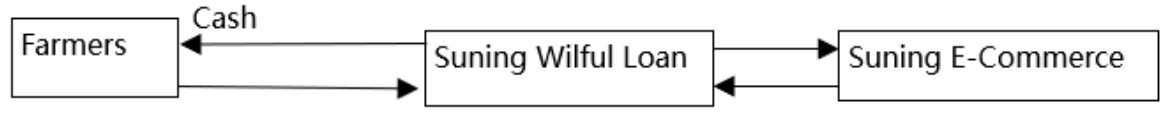

Figure 5 Suning Willful Loan

\subsection{Case Analysis}

\subsubsection{Classification of Agricultural Supply Chain Finance}

For further understanding, we classify and summarize above four patterns according to types of financial products and customers and then provide practical solutions for rural customers. Suning Finance divides its rural customers into the supply side and demand side based on demand and form of funding [22]. While the supply side needs financial support to expand their production, processing, packaging, market and other businesses, the demand side wants to carry out daily expenses. Depend on whether to grant credit loans or cash directly, this classification corresponds to the four financial products launched by Suning Finance.

Table 2. Types of supply chain finance

\begin{tabular}{cccc}
\hline & & \multicolumn{2}{c}{ Types of Financial Products } \\
\cline { 2 - 4 } & & Credit Loan & Cash \\
\hline \multirow{2}{*}{ Types of Customer } & Demand side & Suning Enterprise Loan & Suning Agriculture Loan \\
\cline { 2 - 3 } & Supply side & Suning Willful Pay & Suning Willful Loan \\
\hline
\end{tabular}

\subsubsection{The Motivation of Solutions for Agricultural Supply Chain Finance}

(1) External Stakeholders-Government 
In September 2018, the CPC Central Committee and the State Council issued The Strategic Plan for Rural Revitalization (2018-2022), which made specific arrangements for the first five-year implementation of the Rural Revitalization Strategy. It proposed to increase financial support for agriculture, improve the rural financial system and allocate more financial resources to the key areas and weak links of rural economic development to fulfill the diversified financial needs of Rural Revitalization Strategy. So far, supports have been offered in various aspects to assist the development of rural Internet finance [23]. In 2017, regarding to rural finance, Document NO.1 of the Central Government encouraged financial institutions to actively utilize Internet technology and provided financial services such as small loans, settlement, and insurance for agriculture. Other typical documents and measures are followed.

Table 3. Government documents on rural finance in recent years

\begin{tabular}{|c|c|c|}
\hline Year & Documents & Main Points \\
\hline $\mathbf{2 0 1 7}$ & $\begin{array}{c}\text { Opinions on Pushing Forward the } \\
\text { Structural Reform of Agricultural } \\
\begin{array}{c}\text { Supply Side and Accelerating the } \\
\text { Cultivation of New Driving Forces for } \\
\text { Rural Development. }\end{array}\end{array}$ & $\begin{array}{c}\text { Focusing on the " Agricultural Supply Side Structural } \\
\text { Reform ", we should start from the supply side and } \\
\text { make efforts in the innovation of system and } \\
\text { mechanism, so as to fundamentally solve the most } \\
\text { prominent structural and institutional contradictions in } \\
\text { agriculture. }\end{array}$ \\
\hline \multirow{2018}{*}{$\begin{array}{c}\text { Central Finance Supports Rural } \\
\text { Financial Reform and Development }\end{array}$} & $\begin{array}{c}\text { We will continue to improve and optimize policies and } \\
\text { measures to better support the healthy development of } \\
\text { rural finance. Therefore, considering relevant policies, } \\
\text { we should take advantage of existing policies and } \\
\text { combine the needs of rural financial reform and } \\
\text { development. }\end{array}$ \\
\hline
\end{tabular}

(2) External Stakeholders- Agricultural Practitioners and Rural Consumers

In China's rural areas, the financial supply and demand gap for agriculture, rural areas, and farmers is more than 3 trillion Yuan. What's more, $56.8 \%$ of the farmers are in financial strain and $69.6 \%$ of them find it hard to get loans. However, the satisfaction rate of credit demand of farmers and agricultural production in China is only $27.6 \%$ and $28.5 \%$ respectively. Especially in recent years, with the decrease of small farmers, new types of agricultural operation entities such as professional large-scale households and family farms are emerging gradually [24]. To satisfy such a huge demand, Suning as a profit-oriented enterprise has extended its financial business to the most basic level in rural areas, hoping to release the huge potential of the rural market. As a pioneer in $\mathrm{O} 2 \mathrm{O}$ mode, great efforts have been made to explore solutions suitable for local rural finance and its own development. Suning agricultural supply chain financial products generate strong power for integrating rural scattered capital and enriching the product structure of the rural financial market.

(3) External Stakeholders- Competitors

Meanwhile, as leading enterprises in e-commerce, Ali's agricultural finance provides two different forms of agricultural financial solutions for individual farmers and agricultural enterprises. Namely, micro credit and micro mortgage for individual farmers. Based on agricultural enterprise needs and uses of financial resources, Ali proposed supply chain and industry model, OAO Credit model for them. Ali's thorough closed-loop financial ecology enables it to create a variety of profit models in the field of agricultural finance, which helps agricultural production and farmers get rid of poverty [25].On the other hand, JD.com has been pushing the business of agricultural finance and releasing JD.com Agriculture Loan and JD.com Breeding Loan. JD.com 
Agriculture Loan is characterized as low interest, no mortgage and fast aiming at the problems that poor farmers lack of mortgage assets and simplification of loan procedure. JD.com Breeding Loan which is jointly developed by JD.com and China United Property Insurance Company launched "small loan, insurance and e-commerce" business model [26]. The rural supply chain finance strategy of Ali and JD.com forces Suning E-Commerce to develop rural financial business and further improve the closed-loop ecology of supply chain finance, in conclusion, achieving sustainable development.

(4) Internal Stakeholders- Shareholders

Since the duty of the company is to make profits, financial affairs must be taken into consideration in the decision. Even though enormous capital is need, financial business in rural areas as "Blue Ocean" attracts investment from e-commerce giant represented by Suning, relying on its layout in rural offline e-commerce and the analysis of online behavioral data to carry out comprehensive financial business [27].

As the financial service system of "Agriculture, Rural Areas and Farmers" has been established, the great potential was found in the rural financial market due to the capital need. While Suning started the Internet transformation, its business gradually forms the whole market level to online and offline integration. Suning Square, Suning Convenience Store, Suning Lingshouyundian, Suning Jiwu, and Suning Fresh, have been built to fully meet the diversified consumption demands of different levels of users. Obviously, the expansion of business needs sufficient financial support and that is why Suning has to take advantage of the development of financial business in order to maintain the rapid growth of future revenue and seize the opportunity of development. In addition, it is also the response to the needs of the rural market. To sum up, Suning has enough power to provide flexible products and services for different types of rural customers, which may be a perfect chance for Suning to further integrate the whole industrial chain and build an ideal financial ecosystem.

(5) Internal Stakeholders- Employees

Rational employees have found great potential in the rural market in a long-term perspective. Either decision-makers or executors in Suning E-Commerce have common goals that take advantage of achievement in the rural financial market to develop Suning smart retail. Besides, employees need a company with social responsibility to fulfill their personal value and social value and that is why Suning E-Commerce has always been proactively playing its role in Targeted Poverty Alleviation. Oriented by rural inclusive finance, Suning E-Commerce broadens financial services in rural areas, small enterprises, and real enterprises and finally establishes four directions of financial poverty alleviation which are finance, e-commerce, industry, and science [28]. Suning employees approve their own enterprise, which is also a major power for Suning to steadily promote rural financial supply chain strategy. As the slogan goes: "Work hard and keep working for Poverty Alleviation Battle."

Accordingly, we propose the following proposition:

Proposition 1: Internal and external stakeholders may encourage companies to adopt agricultural supply chain finance measures.

\subsubsection{The Result of Solutions for Agricultural Supply Chain Finance}

(1)Social Performance

Recently, Targeted Poverty Alleviation is becoming an important social issue. With the advantages of resources and technology, Suning rural supply chain finance 
project provides a new solution for the development of the rural market. While implement of the $\mathrm{O} 2 \mathrm{O}$ business model in the rural market has greatly promoted rural employment, consumption, and production. Traditional finance services have hindered farmers from applying for funds, customized financial products and services have provided solutions for leading agricultural enterprises, small and medium-sized agricultural enterprises or individual farmers against funds shortage. Suning Finance has built a real inclusive financial system in rural areas, unblocked credit and loan channels, and realized Targeted Poverty Alleviation [29].

In 2017, Suning E-Commerce was honored as "2017 innovation case of Targeted Poverty Alleviation among listed companies", which further proves that Suning Targeted Poverty Alleviation has been highly recognized by the industry and society. The honor has improved its social reputation and business image, too.

(2) Economic Performance

E-commerce giants, Ali and JD.com have already turned their attention to rural areas and agriculture, forming a new wave of rural finance driven by e-commerce.

Therefore, Suning Finance adopts agricultural supply chain finance to improve market competitiveness. First of all, the development of agricultural supply chain finance has facilitated Suning's business expansion and profit growth. The information of agricultural enterprises expands the Suning user database, which lays a foundation for behavior analysis by means of financial technology and big data, also conducive to Suning's long-term cooperation with leading agricultural enterprises. In the second place, developing the sales channels on Suning platforms online for agricultural products may increase active users of Suning E-Commerce. Finally, financial practice on consuming side end makes Suning crack the hard nut and increase subscriber numbers. Suning Finance offering credit loans and cash loans to individual users has greatly increased desire to consume and at the same time boost sales. Since the interest rate for providing financial services is also an important profit source of Suning, "YIFUBAO" expanded Suning Finance business from payment transaction to credit service, which enhanced the user loyalty and improved the financial closed-loop ecology.

Thus, we state proposition $2 \mathrm{a}$ and $2 \mathrm{~b}$ as follows:

Proposition 2a: Measures of Agricultural finance supply chain enable companies to achieve their social benefits.

Proposition 2b: Measures of Agricultural finance supply chain enable companies to realize their s economic benefits.

\subsubsection{The Influence of Moderator on the Practice of Agricultural Supply Chain Finance}

(1) Support from Big Data Technology

Since the big data technology is a major factor for the steady progress of agricultural supply chain finance, Suning E-Commerce has invested a lot in advanced technologies such as big data, cloud computing, face recognition, artificial intelligence, etc. Finance and science technology are closely inseparable. Big data and cloud computing make it possible to calculate and evaluate personal credit levels while rural financial credit service is incomplete [30].

In our interview, Suning manager emphasized the importance of big data, which is used to provide financial solutions. Artificial intelligence technology based on big data may reduce labor cost, meanwhile, big data technology helps to complete rural personal credit information and confirms user information [31]. Platform data and credit model 
is a typical service supported by big data and data mining technology of the cloud retail financing platform. On the other hand, it makes financial services more convenient and enables the financing platform to make real-time and intelligent.

For financial service providers, the outstanding contribution of big data technology is also reflected in the aspect of risk control. By using advanced risk management systems, the financial services in rural areas can be strongly supervised and the cost can be cut. The risk management system uses multi-dimensional data to control the whole process of supply chain financial services[32]. For companies practicing supply chain financial measures, it is possible to control capital flow and financial settlement if they have established pay channels.

Hence, we propositioned that:

Proposition 3: Advanced big data technology makes it possible for agricultural supply chain finance to help Targeted Poverty Alleviation.

(2) Support from Partners

Apparently, agricultural supply chain finance needs close cooperation among all participants in the supply chain to improve the sustainability of the whole supply chain just as Suning E-Commerce did to cooperate with other enterprises and platforms, such as financial institutions, large agricultural manufacturers and other large retailers. In rural areas of developing countries where credit systems are particularly imperfect, it is difficult to provide assistance to farmers. To collect their offline credit records, Suning cooperates with other entities, such as traditional insurance companies and non-profit organizations [33]. Suning E-Commerce also cooperated with Agricultural Installment to provide loans to scattered farmers outside their database, and this cooperation improves the inclusiveness of financial services and reduce the risk of incomplete credit information. Since Agricultural Installment has vast and extensive information network of offline individuals and small enterprises who need financial assistance and it solves information asymmetry. Cooperation between Suning and Agricultural Installment takes advantage of OAO mode, reduced the loan risk, provides financial services for farmers and facilitates the management of offline information. In short, the application of agricultural supply chain finance emphasizes the importance of cooperation between providers and other entities, breaks the information asymmetry, improves the accuracy of Targeted Poverty Alleviation, and further realizes Targeted Poverty Alleviation, so as to increase inclusiveness and reduce risks.

In the light of the preceding analysis, it is propositioned that:

Proposition 4: Through cooperation with partners, agricultural supply chain finance may help Targeted Poverty Alleviation.

\section{Conclusion}

This article has conducted an in-depth case study of Suning 's practice in agricultural supply chain finance to demonstrate Suning 's outstanding contribution to "Targeted Poverty Alleviation" and the application prospects of supply finance. This paper's contribution to the promotion of agricultural supply chain finance to help targeted poverty alleviation lies in the following aspects. First, this article establishes a link between agricultural supply chain finance and "Targeted Poverty Alleviation". From the perspective of stakeholders, it proves how Suning is promoted by internal and external stakeholders and provides a comprehensive agricultural supply chain financial 
solution to help "Targeted Poverty Alleviation " and how these supply chain financial solutions create social and economic benefits for enterprises.

Secondly, by analyzing Suning's four major agricultural supply chain financial models, and classifying the solutions that act on different objects, the financial services are divided from the demand side and the supply side, providing a strong practice for other companies to implement financial services for poverty alleviation.

Finally, we use the example of Suning agricultural supply chain finance practices to prove that big data technology is indispensable for the development of online supply chain finance services. Since advanced technology methods and big data platforms are the important reasons for Suning's outstanding achievements, big data technology can reduce financial risks and improve service efficiency [34]. Cooperation with other partners provides a real data sour ce for agricultural supply chain finance to help Targeted Poverty Alleviation and promotes the realization of poverty alleviation. In addition, the case selected in this study is an e-commerce enterprise that carries out online supply chain financial services, not a traditional financial institution, which also broadens the research perspective [35].

Although this study sheds new light on supply chain finance and Targeted Poverty Alleviation, several limitations may be addressed in future research. The single case study method is rich and deep, but it lacks universality. Taking Suning as the research sample, the reference significance for other countries is relatively low. In addition, only two moderators are considered in this study, while other possible factors may be ignored. The future research can adopt multi-case study method and consider other moderators. Furthermore, the contribution of this research is exploratory, so future research may apply empirical research to measure the benefits and cost of different agricultural financial solutions at enterprise and supply chain levels.

\section{References}

[1] Xia Yu, Fang Lei, Wei Mingxia. Supply Chain Finance: Theory and the inherent logic [J]. Management Review, 2019,31 (12): 26-39.

[2] Guo Jing. The development of inclusive finance and the effective development of targeted poverty alleviation in rural areas of China [J]. Agricultural Economy, 2019 (04): 94-96.

[3] Ye Xingqing. The key difficulties in implementing the concept of shared development are in rural areas [J]. China Rural Economy, 2016 (10): 14-18.

[4] Zheng Meihua. Rural Digital Inclusive Finance: Development Model and Typical Cases [J]. Rural Economy, 2019 (03): 96-104.

[5] Quirós R. Agricultural value chain finance [M]. Food \& Agriculture Org., 2007.

[6] Wang TR, Lan QG, Chu Y Z. Supply Chain Financing Model: Based on China's Agricultural Products Supply Chain [C] // Applied Mechanics and Materials. Trans Tech Publications, 2013, 380: 4417-4421.

[7] Carnovale S, Rogers DS, Yeniyurt S. Broadening the perspective of supply chain finance: The performance impacts of network power and cohesion [J]. Journal of Purchasing and Supply Management, 2019, 25 (2): 134-145.

[8] Wang Jiao. Research on Internet Finance Helping the Innovation and Development of Rural Finance in China [J]. Agricultural Economy, 2018 (09): 107-109.

[9] Zhu Yiming, Wang Wei. How does inclusive finance achieve targeted poverty alleviation? [J]. Finance Research, 2017, 43 (10): 43-54.

[10] Zhang Yan, Wang Xiaozhi. Models and countermeasures for implementing poverty alleviation by ecommerce in rural poverty-stricken areas [J]. Agricultural Economy, 2016 (10): 58-59.

[11] Yan Fei, Gao Ying, Lu Shan. Research on financial precision poverty alleviation from the perspective of big data[J]. Computer Knowledge and Technology, 2019, 15(24): 20-21.

[12] Dong Yufeng, Chen Junxing, Du Chongdong. Poverty Alleviation by Digital Inclusive Finance: Theoretical Logic, Model Construction and Promotion Path[J].Southern Finance,2020(02):64-73.

[13] Freeman, RE (1984). Strategic Management: A Stakeholder Approach. Boston, MA: Pitman. 
[14] Angela Hwang,Chantal Veira,Stefano Malvolti,Thomas Cherian,Noni MacDonald,Christoph Steffen,Ian Jones,Alan Hinman,Carsten Mantel. Global Vaccine Action Plan Lessons Learned II: Stakeholder Perspectives[J]. Elsevier Ltd,2020,38(33).

[15] Banerjee, SB (2001). 'Managerial perceptions of corporate environmentalism: interpretations from industry and strategic implications for organizations'. Journal of Management Studies, 38, 489-513.

[16] Doh, JP and Guay, TR (2006). 'Corporate social responsibility, public policy, and NGO activism in Europe and the United States: an institutional-stakeholder perspective'. Journal of Management Studies, $43,47-73$.

[17] Sharma, S. and Henriques, I. (2005). 'Stakeholder influences on sustainability practices in the Canadian forest products industry'. Strategic Management Journal, 26, 159-80.

[18] Wu Weijia. Opportunities and risks of the "Internet + " model— - Taking Suning Tesco as an example [J]. Accounting and Communications, 2016 (20): 82-84.

[19] Shuangshuang. On Suning Financial's O2O Integration of Retail Value Chain [J]. Business Economics Research, 2018 (02): 159-161.

[20] Xin Yaoyao. Institutional change and generation logic of China's rural financial poverty alleviation [J]. Gansu Social Sciences, 2019 (03): 151-156.

[21] Yang Qi. Characteristics, Development Obstacles and Countermeasures of Rural Internet Finance in China [J]. Research on Technology Economy and Management, 2019 (03): 124-128.

[22] Du Yonghong. Research on the Network Poverty Alleviation and E-commerce in the Rural Area under the Background of Rural Revitalization Strategy [J]. Reality, 2019 (03): 97-108 + 112.

[23] Wang Jiao. Research on Internet Finance Helping Rural Financial Innovation and Development in China [J]. Agricultural Economy, 2018 (09): 107-109.

[24] Wang Hanjie, Wen Tao, Han Jiali. Research on the Synergy Effect of Fiscal Policy on Poverty Reduction in Rural Areas in Rural Areas [J]. Theory and Practice of Finance and Economics, 2020, 41 (01): 93-99.

[25] Bao Wenshuang. Internet financial platform fills the gap in rural financial demand [J]. People 's Forum, 2019 (05): 78-79.

[26] Liu Jun. Rural Extension of Internet Finance and Incentive System Response [J]. Journal of Anhui University (Philosophy and Social Sciences Edition), 2017, 41 (05): 112-119.

[27] Wang Gangzhen, Wu Xu. Research on the Internet Financial Poverty Alleviation Model Based on Ecommerce Platform- Taking Jingdong as an Example [J]. Journal of University of Electronic Science and Technology of China (Social Science Edition), 2018, 20 (05): 23-28.

[28] Li Lujia. Financial risks and enlightenment of Suning 's business model transformation [J]. Fujian Forum (Humanities and Social Sciences Edition), 2019 (04): 48-56.

[29] Liu Jinyi, Liu Chunyang. Rural poverty reduction effect of digital inclusive finance: effect and mechanism [J]. Economics and Finance, 2020 (01): 43-53.

[30] Gu Zheng, Shi Airan. Research on financial technology helping to prevent and control financial risks [J]. Audit and Economic Research, 2020, 35 (01): 16-17+ 11.

[31] Cheng Xuejun. Internet consumer finance: technology application, problems and regulatory countermeasures [J / OL]. Contemporary Economic Management: 1-17 [2020-03-28]. Http://kns.cnki.net/kcms/detail /13.1356.F.20200221.1453.004.html.

[32] Zhou Yueshu, Da Yujie, Yu Ying. Analysis of the operation of the "Internet + agricultural industry chain" financial innovation model — Taking Dabei agricultural and pig industry chain as an example [J]. Agricultural Economic Problems, 2020 (01): 94-103.

[33] Weber, R.; Musshoff, O. Can flexible agricultural microfinance loans limit the repayment risk of low diversified farmers? Agric. Econ. 2017, 48, 537-548.

[34] Arner, DW; Barberis, J.; Buckley, RP the evolution of Fintech: A new post-crisis paradigm. Geo. J. Int Law 2015, 47, 1271.

[35] Liu Siwei, Xiang Yuteng, Tang Hongtao. Research on the Non-Linear Regulation Effect of Financial Development on Poverty Alleviation — Based on the Evidence of 285 Prefecture-level Cities in China [J]. Economic Issues, 2019 (12): 34- 43. Author 1, A.B.; Author 2, C.D. Title of the article. Abbreviated Journal Name Year, Volume, page range. 